\title{
LA ARTICULACIÓN DE LAS PRÁCTICAS \\ SOCIALES A PARTIR DE LAS MODALIDADES DE MEDIACIÓN DEL DISEÑO EN EL ESPACIO DE LA PLAZA DE CAYZEDO Y LA PLAZOLETA DEL
} CENTRO COMERCIAL UNICENTRO, EN SANTIAGO DE CALI

\author{
Mauricio Guerrero \\ Profesor de la Facultad de Derecho y Ciencias \\ Sociales \\ Universidad ICESI \\ mauriciokempes@gmail.com
}

\section{Resumen}

El siguiente artículo tiene por objeto describir el conjunto de prácticas sociales presentes en dos escenarios que implican dos modalidades de apropiación del espacio público en la ciudad de Santiago de Cali: La Plaza de Cayzedo y la Plazoleta del Oasis, ubicada en el centro comercial Unicentro. La descripción propuesta se enfoca en el rastreo de la relación que establecen los usuarios con las plazas y los objetos presentes en éstas, entendidos como objetos de diseño que median la experiencia y significación de lo social.

Palabras clave: sociología, diseño, objetos, usuarios, relaciones, prácticas, sentidos, significados, espacios.

\begin{abstract}
:
This article attempts to describe the conjunct of social practices presents in two stages that implies two modalities of appropriation of public space in Cali: the Plaza de Caycedo and the Plazoletadel Oasis, in Unicentro. The description focused in the search of the relationship established between the users with the plazas and its objects, understood as objects of design that are in the experience and signification of the social.
\end{abstract}

Keywords: sociology. Design, objects, users, relationships, practices, senses, meanings, spaces. 


\section{Introducción}

Los resultados de la investigación que aquí se presentan, se centran en el estudio de la relación que se establece entre los objetos de diseño presentes en dos modalidades del espacio público en la ciudad de Santiago de Cali, y las prácticas sociales que, mediadas por esos mismos objetos de diseño, se actualizan en dichos lugares ${ }^{1}$. Para este fin, se abordaron dos espacios. El primero de ellos corresponde al espacio semi-público que representa la "nueva" plazoleta del centro comercial Unicentro ${ }^{2}$. El segundo es el que corresponde al espacio de socialización tradicional de la plaza pública (Plaza de Caycedo).

Por medio de un método mixto, que hace uso de técnicas etnográficas, de una caracterización de objetos de diseño basada en la teoría de los usos y funciones de los objetos de diseño (Moles,1975), de la interpretación semiológica de dichos objetos (Panofsky, 1998) y del análisis a los reportes de entrevistas y diálogos sostenidos con usuarios de estos espacios, la investigación se orientó a la identificación de las matrices relacionales por medio de las cuales se constituyen sentidos y de los significados del espacio y de sus usos por parte de los agentes humanos que los visitan, recorren o habitan.

En este sentido, el análisis se dirigió, concretamente, a la elicitación de las formas en que el diseño opera como: a) práctica social; b) mediador de las relaciones sociales, c) agente funcional en el contexto de matrices relacionales; d) código a través del cual se transmiten y expresan valores, significados y sentidos que devienen representaciones del mundo y dispositivos por medio de los cuales se semantiza la experiencia de los sujetos; y e) dispositivos-signos que los sujetos se apropian en función de sus necesidades, expectativas y saberes previos en una situación específica (Eco, 2000).

A partir de dicha exploración, se hace posible, al final de este artículo, describir, en términos generales, cuáles son los rasgos fundamentales que presenta el desplazamiento de las prácticas sociales en el espacio público a través del paso de la plaza pública a la plazoleta del centro comercial.

Esta elección de espacios se basa en la consideración de la importancia que la Plaza de Caycedoreviste en términos de conformación tradicional de la sociabilidad en el espacio público en la ciudad de Cali. En dicha plaza confluyen todos los elementos que caracterizan el modelo tradicional de este tipo de espacios dentro del marco histórico y cultural de un trazado urbano de origen hispánico(Pérgolis, 2000).

Por su parte, el centro comercial Unicentro, que es uno de los más antiguos de la ciudad, aparece como espacio idóneo para la exploración de dinámicas racionales de intervención desde el diseño, en la medida en que ha sido reconfigurado arquitectónicamente en múltiples ocasiones, siempre desde una mentalidad que otorga explícitamente al diseño la función de mediador y modelizador de la experiencia de consumo.

La investigación en la que se articula la observación de estos dos espacios es el producto del trabajo coordinado de un grupo de profesionales e investigadores procedentes de diversas áreas del conocimiento (diseñadores, sociólogos), cuyos intereses confluyen en la exploración de las diversas dinámicas en las que el diseño opera como agente mediador de sentido y de sociabilidades en la sociedad contemporánea. 


\section{Consideraciones sobre el abordaje diseño como dispositivo de mediación social}

Con miras a explicitar el tipo de abordaje de los objetos de estudio que caracterizó a la investigación que aquí se presenta, es necesario establecer de antemano que éste se basa en la asunción de que el diseño opera no sólo como agente de mediación y dispositivo fundamental de la producción de los sentidos que caracterizan a los espacios públicos, y a las experiencias que en estos pueden tener lugar; sino, además, que es en sí mismo, y en principio, una práctica social caracterizada por múltiples dimensiones y funciones (Press y Cooper, 2009).

El diseño posibilita modelizaciones de la experiencia mediadas por "enunciados" en su mayor parte no verbales, pero perfectamente efectivos y en gran medida eficaces, en tanto corresponden a códigos de apercepción, manipulación y apropiación pre-determinados por gramáticas y matrices formales-culturales que son compartidos por una comunidad.

Estas dimensiones y funciones del diseño son correlativas y dinámicas, y se actualizan en la tensión constante entre las gramáticas del hacer y percibir(De Certeau, 2006) que los objetos de diseño encarnan y simbolizan; y los distintos usos que les dan los diferentes agentes sociales, desviando en mayor o menor medida los sentidos que suponen dichas gramáticas, pero al mismo tiempo reproduciéndolas en sus aspectos fundamentales.

Estos sentidos se pueden rastrear y analizar al observar cómo las relaciones mediadas por los objetos de diseño, re-significan los hábitos y prácticas de los actores sociales (Latour, 2008). Por ello nuestro énfasis en el estudio del diseño como conjunto de prácticas sociales está motivado por la manifiesta necesidad de adecuar la investigación sociológica a las dinámicas de cambio social contemporáneas, entre las que se destaca — como signo de ese mismo cambio - la manifiesta relevancia del diseño y su influjo en los diversos contextos sociales en que tienen lugar las prácticas de lo público.

Para llevar a cabo la descripción sociológica de dichas dinámicas de cambio y producción de lo social desde el abordaje y el tipo de exploración que a grosso modo han sido descritos anteriormente en este mismo artículo, se hace necesario, evidentemente, el desarrollo de acercamientos teórico-metodológicos al objeto de estudio que resulten idóneos para dar cuenta de las matrices relacionales que subyacen a las funciones del diseño en los espacios de uso público.

En este sentido, en primera instancia, se asume al diseño como campo de prácticas de mediación social. En este campo confluyen diversos agentes (entre los que se destacan los objetos de diseño, los diseñadores, los usuarios), que establecen entre sí vínculos e interrelaciones dinámicas, los cuales no son unidireccionales ni responden a esquemas fijos de funcionamiento, y que se articulan, a su vez, en prácticas de apropiación del espacio y modelos de experiencia determinados, en nuestro caso, por el carácter socialmente constituido de las plazas públicas y las plazoletas de los centros comerciales.

Los sentidos y significados de los espacios de uso público, y de las experiencias e intercambios (procesos de socialización) que en estos tienen lugar, se anclarían básicamente en las matrices relacionales sugeridas por las prácticas de diseño. Esto es cierto sobre todo para espacios que poseen ya un carácter tradicional en el 
espectro de los modos de experimentar y habitar lo social urbano, tales como la plaza pública — caracterizada por la gratuidad y su inserción en las representaciones de lo "tradicional” y público — y el centro comercial — caracterizado por su pertenencia al universo de las prácticas comerciales y la empresa privada - (Silva, 2002).

Del contraste entre ambos tipos de espacio estudiados - el público tradicional de la plaza y el privado comercial (destinado al uso público restringido, o semi-público) del centro comercial— surge la posibilidad de elucidar modalidades de aprehensión de las gramáticas y posibilidades del diseño, que están a su vez estrechamente relacionadas con diversas actividades políticas y económicas, y con los dispositivos estratégicos que planifican los lugares y los dotan de sentidos pre-existentes acordes a las voluntades de sus poseedores o realizadores (Yori, 2007).

La noción de objetos de diseño ha resultado esencial para dar cuenta del conjunto de procedimientos y dinámicas implicadas en esta relación entre la configuración del lugar (semiosis del espacio) y la intervención del diseño en el mismo. Es a partir de esta herramienta teórico-metodológicaque las intervenciones de este campo de prácticas sociales en los espacios de uso público han podido ser tratados como fuentes e indicadores que sirven de insumos a los procesos sociológicos de decodificación de las distintas actualizaciones que se presentan, en cada uno de los espacios estudiados, para la relación entre la producción del sentido de lo social y el diseño.

\section{Nociones sobre la articulación entre objetos de diseño y espacio público y semi-público}

El análisis central de este trabajo debe empezar por la elicitación de la diferencia fundamental en lo que respecta a la caracterización de los dos espacios observados. Esta diferencia estriba, principalmente, en la adscripción de la Plaza de Caycedo a la noción de espacio público (en la medida en que está consagrado al ejercicio de la ciudadanía y se relaciona estrechamente con la construcción de la identidad histórico-social en el marco del dispositivo arquitectónico y urbanístico de la ciudad), y la de la nueva plazoleta del centro comercial Unicentro a la noción de espacio semi-público (en la medida en que está diseñado para el uso por parte del público, pero responde a intereses privados y es instrumentalizado en función de esos intereses, que corresponden a las motivaciones comerciales de sus propietarios).

Los espacios públicos revisten el carácter de lugares de identidad (ya que los individuos pueden reconocerse y definirse en función de éste), de relación (toda vez que posibilita sociabilidades recurrentes que adquieren sentido en su contexto), y de historia (signada por la inserción del lugar en un dispositivo arquitectónico en el que los edificios y trazos urbanísticos han sido semantizados como índices y símbolos de la historia de la ciudad). Esta articulación de dispositivo urbanístico e histórico en el que se construyen las prácticas y representaciones de la ciudadanía, deben ser asumidos como un derecho de los habitantes de la ciudad (Viviescas, 2000). En este último aspecto, se marca una de las diferencias fundamentales del espacio público con respecto a los espacios semipúblicos, en los que el acceso no está garantizado por virtud de la libre apropiación de lo comunitario, sino por los códigos que estructuran la actividad comercial. 
Complementariamente, el segundo paso para la caracterización de ambos espacios compete a la descripción de la forma en que cada uno de estos actualiza la noción de macro-objeto, propia de la teoría del diseño. Esta noción tiene la función de constructo heurístico a partir del cual se hace posible el estudio sistémico, en torno a la noción de diseño, del espacio arquitectónico y sus contenidos.

Cada uno de los niveles de este sistema comporta, a su vez, un conjunto de objetos de diseño, clasificables según su relación con el cuerpo humano y el espacio. En esta categorización a los macro-objetos los complementan los micro-objetos y los objetos equivalentes (Moles, 1975).

Tales presupuestos conceptuales allanan el camino para la identificación del sistema de relaciones dinámicas e interactivas a través de las cuales son actualizadas - en el uso cotidiano de los espacios y de los objetos que los integran (Berger y Luckman, 2001) - las diversas prácticas sociales que al investigador de la articulación entre el diseño y lo social le es dado interpretar e inferir a partir de la observación y la aplicación de instrumentos específicos, diseñados para recabar información cualitativa con respecto a las acciones, expectativas, y saberes de los agentes humanos que "habitan" transitoriamente el centro comercial o la plaza pública.

Por su parte, el acento en el diseño como práctica, y en los objetos que dicha práctica produce como mediadores sociales, supone que estos son agentes fundamentales en la mayor parte de los intercambios por medio de los cuales se producen, reproducen y transforman las relaciones sociales (Martín, 2002).

Simultáneamente, los objetos de diseño, en tanto que significantes, cumplen con la función de hacer factible la actualización (semiosis) de los códigos sociales y los sistemas de valores que organizan las prácticas de los sujetos (los intercambios), y que encuadran a estos en grupos diversos, dependientes de su propia relación con las propiedades formales, materiales y simbólicas de los elementos con los que entran en relación en el marco de la vida cotidiana (Verón, 1993).

La tercera dimensión del estatuto que se otorga a los objetos de diseño en la investigación que aquí se presentan, y que es consecuencia de las anteriores, es la de fuentes de información. En este sentido, se considera que tales objetos contribuyen a "dar forma" a las representaciones y las prácticas de los agentes humanos con respecto a sí mismos, a otros agentes humanos, a los agentes inanimados que incluyen en sus intercambios, y a los espacios de socialización en los que esos intercambios tienen lugar.

Consecuencia de las reflexiones teórico-metodológicas hasta aquí descritas es el hecho de que el diseño deba ser estudiado también como una variable importante en el seno de las problemáticas relativas a las dinámicas de poder que están en juego a través de las interpretaciones del mundo válidas para diversos subsistemas relacionales (centro comercial-plaza pública).

Estas operaciones de interpretación de la realidad, por su parte, nos remiten a las estrategias emanadas del campo de los expertos (diseñadores, arquitectos) para establecer gramáticas de la conducta y el uso de los espacios y los objetos. Tales estrategiasencuentran su contrapartida y complemento en los órdenes tácticos de acción por medio de los cuales los sujetos particulares se apropian de lo dado. El resultado de la 
relación de ambas voluntades es una tensión constante entre la espontaneidad del uso y la predeterminación que supone la función. Es en y por esta tensión, que los objetos de diseño actúan como mediadores sociales (Sánchez, 2001)

\section{El centro comercial y la plaza pública como objetos de diseño: caracterización de las funciones del diseño en la mediación y producción de los sentidos y significados del espacio.}

Los presupuestos conceptuales expuestos en el apartado anterior sirvieron de base al análisis de las prácticas (de diseño, comerciales, del tiempo de ocio) que pudieron apreciarse durante la observación de los espacios estudiados, y que fueron identificadas por medio de la aplicación de entrevistas.En primera instancia, se presenta el reporte de la observación etnográfica del espacio público Plaza de Caycedo.

Plaza de Caycedo

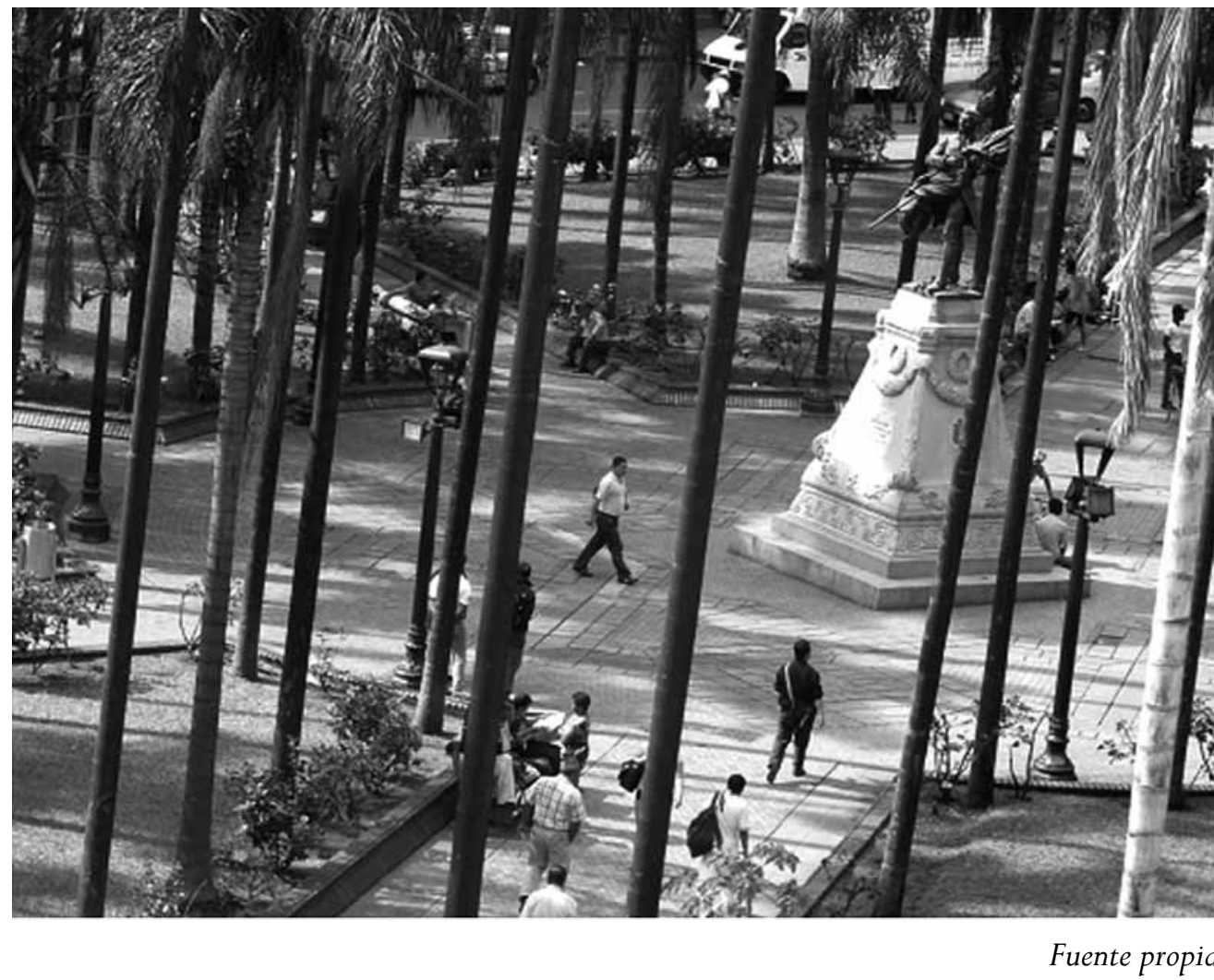

La Plaza de Caycedo, otrora llamada Plaza Mayor (durante la Colonia), o Plaza De la Constitución (desde los inicios de la vida republicana hasta 1913) tiene un área de aproximada de $10.000 \mathrm{mt}$. A partir de la fundación de Santiago de Cali, este espacio ha sido un punto estratégico y eje simbólico de la ciudad en lo que concierne a los diferentes estamentos que componen la estructura social. En la actualidad, y después de varias transformaciones arquitectónicas, su planta se asemeja a la de un parque: está dividida por una serie de diagonales que organizan el flujo de los usuarios y delimitan las zonas verdes que la componen. 
La Plaza de Caycedo es un espacio céntrico abierto, rodeado por calles agitadas, por edificios, oficinas y locales en los que la velocidad es la característica fundamental de las acciones y las prácticas, las cuales se enmarcan, dado el carácter del sector, en el dominio de las intercambios y las relaciones comerciales, laborales, o político y económico administrativas.

Tradicionalmente el centro de la ciudad no es considerado un territorio para el ocio o un foco de entretenimiento y diversión. Lo que allí se hace suele estar determinado por necesidades prácticas y por la aglomeración, en ese sector, de buena parte de los centros de atención al cliente de las empresas públicas o privadas, o de los centros de distribución mayorista o al detal de productos, bienes y servicios que integran el espectro de los consumos cotidianos de buena parte de los habitantes de la ciudad.

Sin embargo, tras las fronteras difusas pero efectivas que suponen las calles 11 y 12 , y los pasillos peatonales correspondientes a las carreras 5 y 4 (corazón del centro histórico de la ciudad), se verifica un cambio significativo en la forma como hombres y mujeres se apropian del espacio, en el tipo de prácticas que llevan a cabo, en cómo lo hacen, y en el orden de sus itinerarios.

En este espacio un flujo incesante de personas recorre diagonalmente la cuadrícula para acortar camino en sus itinerarios de negocios, trabajo o comercio que corren curso entre distintas oficinas e instalaciones. La velocidad de los desplazamientos es constante, pero los viandantes, a diferencia de los que se afanan en las aceras y calles aledañas, no parecen tener prisa al momento de atravesar los pasillos en los que, sentados en las bancas o en los bordillos de las zonas verdes, se encuentran otras personas, hombres y mujeres, solitarios o en grupo, que parecen simplemente dedicarse a ver pasar la tarde, a conversar o a guardar silencio.

La mayor actividad la despliegan los vendedores ambulantes. Ofrecen café, llamadas a teléfonos celulares, dulces, refrescos, algunas frituras y alimentos preparados de manera casera que son movilizados en carros de compras o viejos coches de bebé habilitados para esa función. Ellos tampoco dan muestras de prisa. Se estacionan en un punto, y de vez en cuando vocean su producto. La Plaza es un lugar de ritmos lentosque entran en contraste con los que caracterizan al resto del centro de la ciudad.

\section{Los espacios de la Calma}

En una esquina de la plaza, del otro lado de la calle 12, se encuentra la Catedral. En el interior de la iglesia, algunos fieles se entregan a las prácticas de la devoción. Lugar de silencio y contemplación, la Catedral se erige como marca de la centralidad simbólica y funcional que en el seno de la cuadrícula urbana, y de la historia de la ciudad, detenta la plaza. Al mismo tiempo, sirve como contraste efectivo para el observador que podría verse tentado, ante la inusitada calma que encuentra en la plaza, a suponer que los que allí pasan las horas de la tarde llevan a cabo prácticas ligadas a algún tipo de ejercicio contemplativo. 
No hay tal. Los hombres y las mujeres que hacen de la plaza su hábitat urbano, en el que se sustraen de la prisa de la ciudad, de las dinámicas de los locales comerciales, y de la prisa que marca los desplazamientos en los alrededores, no contemplan ningún objeto en particular, no se entregan a ninguna devoción. Su hacer es más terrenal, cotidiano.

Para ellos, casi todos los puntos y lugares de la plaza son buenos para el reposo modalidad fundamental de su acción-, con excepción de las zonas verdes, las cuales suelen ser respetadas por los transeúntes. La apropiación del espacio que aquí se realiza está determinada por esta voluntad o fatalidad del reposo que lleva a una población en su mayoría adulta a confluir en las bancas y los bordillos durante las horas tradicionales del trabajo y la oficina.

Sólo los vendedores ambulantes se dedican aquí a una actividad económicamente productiva, pero ellos también se insertan en esta modalidad de apropiación del espacio público que está modelizadapor la calma y la tranquilidad. Sus itinerarios son lentos, y poco agresivos (no imponen su producto a los habituales de la plaza, a los que parecen conocer de tiempo atrás, ni a los viandantes), de espera. Saben que los consumidores los llamarán eventualmente.

Unos y otros, habitantes diurnos de la Plaza y vendedores ambulantes, parecen integrar un sistema de sociabilidades y reconocimientos que tiene su asiento en la apropiación, por parte de unos y otros, del espacio público; y en el establecimiento concomitante de reglas de una gramática y un tono de los intercambios que son propios de este lugar en la medida en que su carácter abierto los permite (Yori, 2007).

Conforme pasan las horas, y los ritmos del centro de Cali van cambiando, esta partida de habitantes y trabajadores informales permanece igual. Los que están sentados conservan sus puestos y se entretienen en animadas conversaciones de grupo; los solitarios siguen absortos en su silencio, los vendedores hacen esporádicas rondas y regresan al punto de partida.

\section{La ausencia del lujo}

Las vestimentas de la población que hace de la plaza el sitio en el que transcurre su tarde son humildes. La brisa o alguna persona traen de vez en cuando el olor a orín, que se ha ido reconcentrando en diversos lugares y parece no incomodar a nadie, como tampoco lo hacen los efluvios de lixiviado que surgen de los botes de la basura, cerca a los cuales se ubican varios grupos de conversadores.

Los vendedores y vendedoras disponen de tarros plásticos para conservar el café que ofrecen. Cuando alguien requiere sus servicios, destapan el tarro y sirven la bebida en vasos plásticos desechables. Estas prácticas contrastan abiertamente con las del local de café del otro lado de la Plaza, en el que oficinistas y transeúntes son atendidos en un espacio reducido pero poseedor de los pequeños signos del confort y el diseño (muebles, barra, disposición de los postres en el mostrador, menús, señalética) que confluyen en la práctica del local de comidas destinado a servir como sitio de paso y reposo durante el descanso del trabajo o las diligencias. 
La ausencia del mostrador, de las sillas, de barrera alguna entre vendedor y consumidor hace de la plaza un lugar en el que los intercambios económicos toman un cariz personal y directo. En el momento de la venta, el discurso (verbal y paraverbal) de los vendedores es cálido, estructurado en torno a los signos de la confianza, carente de afectación o distancia. Ejemplo de ello son elocuciones del tipo "claro, mi amor, cómo no. Bien calientito", que expresa la vendedora mientras sonríe, motivando la complicidad del cliente.

Esta ausencia de equipamentos (es decir, de objetos de diseño destinados a modificar el espacio estratégicamente), y la sencillez que se manifiesta en el vestuario y los lenguajes del cuerpo de los habitantes de la plaza no son óbice, pues, para que el tiempo que aquí se pasa sea agradable. De más están los signos del gusto, el diseño y el confort que ofrecen, bajo la formalidad de objetos de diseño (Heskett, 2005), los locales aledaños orientados a atender a los oficinistas de la zona.

\section{El placer de la conversación}

La conversación amena juega un papel esencial en el orden de las sociabilidades de la Plaza. Por doquier se arman grupos que se dedican a la charla, puntuada por la risa como elemento fundamental. Ésta llega desde todas las direcciones, a veces estentórea (una vendedora que ríe ante los avances corteses de un hombre), en ocasiones general; se origina en los grupos que intercambian anécdotas en las que se incluyen los interlocutores o terceras personas. Los temas abarcanun amplio espectro, pero son recursivos los relacionados con el trabajo, los eventos que se han vivido o presenciado, los hechos y milagros de los habitantes de la Plaza que sirven de factor aglutinante para esta comunidad.

La risa es el marcador que divide lo dicho en períodos, y es el signo de la adecuación de lo enunciado a los requerimientos de la situación. Incluso los discursos que entran en el registro genérico de la queja (por condiciones sociales, económicas, laborales) se elaboran de manera que se integren al tono general de alegría y esparcimiento.

Una población de trabajadores informales, desempleados y jubilados, la mayor parte de ellos presumiblemente sin educación superior, pone así en prácticauna modalidad de apropiación del espacio público y de sociabilidad, marcada por el disfrute y el intercambio de relatos acerca de las vicisitudes de lo cotidiano, narrado desde el humor, el chisme, y la anécdota.

\section{La política invisible}

Este ejercicio compartido de la calma y la tranquilidad, de la conversación y la seducción lúdica y efímera equivale a una práctica política invisible que realizan los habitantes cotidianos de la plaza. Esta práctica discursiva es importante en la medida en que replica las dinámicas tradicionales de las plazas antiguas, en las que el diálogo, el rumor, el intercambio de ideas entre los agentes del discurso establecía representaciones y valoraciones del sistema social (Silva, 2002), que en muchos aspectos resultaban divergentes con respecto a los sentidos que pretendían movilizar e imponer sobre una comunidad los discursos oficiales. 
En este caso, esa función de la plaza como lugar de la libre expresión se observa a través del tono de descreimiento o abierto distanciamiento con respecto a los discursos oficiales. El habitante de la plaza no se ocupa mayormente de lo que le dicen los medios de comunicación, como no sea para comentarlo manifestando su incredulidad o su fascinación en el caso de que se trate de relatos grotescos o sensacionalistas que lee en los tabloides gratuitos que circulan por la ciudad.

Lo que en realidad le importa a los habitantes de la plaza es su pequeño mundo. Tal actitud señala una forma de posicionarse con respecto al poder. Desposeídos de los medios para hacer efectivo su discurso más allá del rumor y la queja compartida en el seno del grupo de los que no hacen nada; de las condiciones materiales, culturales y económicas que se requieren para interactuar en otros espacios académicos, políticos y profesionales, estos hombres y mujeres se apartan de aquello sobre lo que no tienen ningún poder de decisión.

En el conocido discurso del poder y la dominación se podría decir que son dominados que han encontrado una táctica que les permite obviar, o aunque sea minimizar, las implicaciones de su condición. Esa táctica es producto de su ausencia de recursos, de un lugar propio, un saber autorizado, la pertenencia a estructuras institucionales en las que pudieran construir una representación de sí mismos más acorde con los ritmos de la ciudad apurada y productiva.

Como toda táctica, la de la calma, la conversación, la consagración a observar el paso del tiempo desde la tranquilidad de la plaza, se presenta como orden de acción que se opone a las estrategias normalizadoras de los discursos del poder oficial y de las representaciones y prácticas que articulan, estratégicamente, el deber ser de los sujetos como ciudadanos, sus usos del tiempo, sus formas de transitar por los lugares e insertarse en los espacios (Delgado, 1999).

En consecuencia, puede leerse ese "no hacer nada", ese goce del paso del tiempo, como un hacer político (Duque, 2001), paradójicamente establecido en función de la sustracción, por parte del sujeto, de todo aquello a lo que no tiene acceso, incluyendo la articulación de la circunstancia y el espacio mediadas por la intervención objetual del diseño.

De esta manera, lo que se actualiza en la plaza día tras día es algo más y algo menos que una rebeldía, una recusación del orden cotidiano de lo social estructurado por el diseño como práctica profesional, y una manifestación de las diferencias que instaura ese mismo orden. La plaza es un macro-objeto que no impone su gramática a las acciones de los sujetos, sino que se usa de forma "natural", tal y como ocurre con aquello a lo que se tiene derecho. 


\section{Plazoleta del Oasis en el Centro Comercial Unicentro}

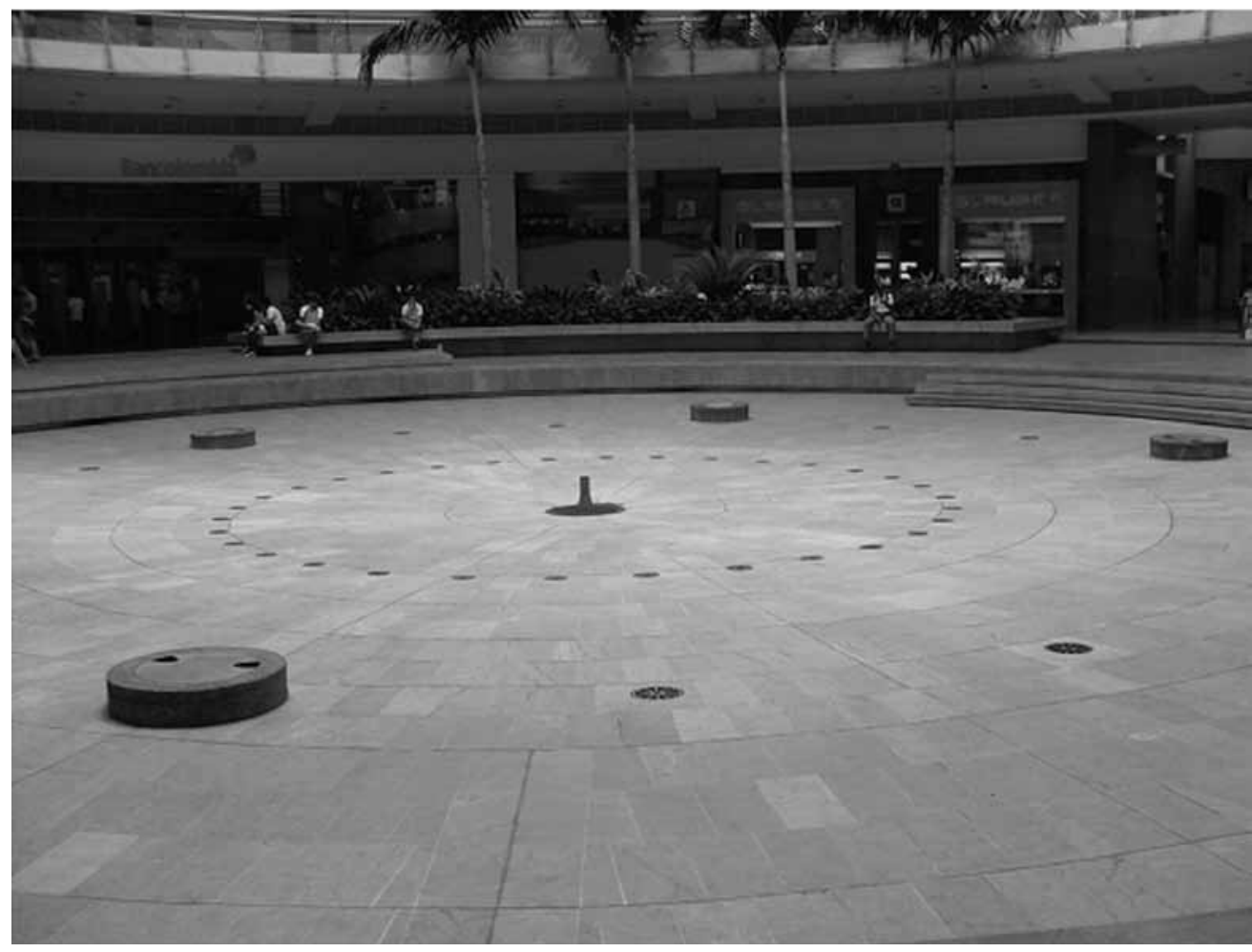

Fuente propia.

La plazoleta del Oasis, en el centro comercial Unicentro, es un espacio arquitectónico de aproximadamente $900 \mathrm{mts} 2$ que hace parte del proceso de la última ampliación del dispositivo comercial que la alberga. Junto con el edificio que la circunda, es parte de una propuesta estética centrada en la confluencia entre arquitectura y diseño, que en la actualidad constituye la apuesta estilística característica del proyecto de remodelación de todo el complejo comercial.

En este sentido, la plazoleta nueva de este centro comercial es un espacio arquitectónico comercial producto de un pensamiento estratégico. Su disposición circular y simétrica, la posibilidad de vigilarla desde los niveles superiores del ala del centro comercial a la que pertenece (que tiene forma de torre), la presencia de las cámaras de seguridad, las rondas sutiles de los guardas, hacen de ésta un sitio fácilmente monitoreable.

Este macro-objeto está destinado a ser experimentado como un espacio tranquilo, inserto en el seno de un espacio comercial privado, en el que el confort, la tranquilidad, el disfrute del espacio ajeno (privado) son los aspectos fundamentales de la experiencia del tránsito por su pasillo circular o por el anillo interno que rodea la fuente central. En torno a ésta se articulan las actividades y prácticas que tienen lugaren los cafés (dos), en los bordes del anillo que la rodea (lugar de descanso y conversación) o en los locales exteriores. 
El espacio se organiza, sintáctica y semánticamente, a partir de la invitación a la contemplación o el goce del espectáculo de diseño que ofrece dicha fuente. Alrededor, oficinas bancarias con filas de cajeros automáticos sin cabina, almacenes deportivos, de ropa y accesorios de diseñador (como, por ejemplo, un local de la firma Carolina Herrera), y dos cafés que se ubican en puntos opuestos, ofrecen al usuario sus servicios y productos.

Todos estos locales están caracterizados, por el hecho de estar estructurados ellos mismos como macro-objetos de diseño. La apariencia de cada uno denota un estilo y connota un conjunto de valores relacionados con la marca (o las marcas) a la(s) que sirven.

En consecuencia, la relación de los usuarios con el espacio arquitectónico, y su consumo de bienes y servicios, los introducen en un sistema de intercambio y actualización de valores referidos al universo simbólico que organiza el sistema comercial privado del mall.

Un saber previo y un capital cultural específicos son requeridos (y/o supuestos) como conjuntos de disposiciones y actitudes que subyacen al paseo o la visita al centro comercial. Resultado de ello es la manifestación de la pertenencia a un universo de prácticas cuya diferencia más evidente con respecto al de la plaza pública estriba en el hecho de que en el primero todo remite a un nombre, un estilo, la enunciación de la exclusividad en concordancia con la cultura de masas propia del sistema cultural del centro comercial.

Los usuarios de la plazoleta del centro comercial no toman posesión del espacio como habitantes del mismo en la medida en que sí lo hacen los asiduos del espacio público. Esto ocurre porque el espacio arquitectónico del centro comercial es ajeno y el contrato que subyace a su uso establece que el tránsito por el mismo reviste el carácter de la visita.

Este contrato ofrece el disfrute de las particularidades estéticas de las instalaciones, y del lujo y el confort que éstas ofrecen, pero no permite que el espacio sea apropiado como lugar de habitación cotidiana, al contrario de lo que ocurre en la plaza pública.

Un sinnúmero de prohibiciones tácitas organizan los comportamientos y las prácticas de los sujetos impidiendo usos como los de la laza pública. Entre éstas, la que compete al aparato de seguridad que vigila el centro comercial, y la expectativa de la compra que se extiende sobre todo aquel que ingresa al mismo, son quizá las más determinantes. Es por ello que la presencia de los visitantes es transitoria. Son pocos los que se detienen por más de una hora en el anillo que rodea la fuente, o en los dos cafés ubicados en los extremos de la misma.

La plazoleta es un lugar de paso en el que pequeños grupos (de entre dos y cuatro personas) toman un descanso y, si cuentan con la posibilidad económica de comprar un café, un jugo, una cerveza (a costos mucho más altos que en el centro de la ciudad), se sientan un rato a conversar en alguna de las mesas diseñadas y dispuestas para tales fines.La mayor parte del público, sin embargo, corresponde aquienes requieren una permanencia reducida. Se trata de personas que necesitan de los servicios de los cajeros electrónicos que se encuentran en la esquina del pasillo por el que el flujo llega a la plazoleta. 
En este pequeño reducto el flujo es constante. Alrededor, se puede observar cómo pequeños grupos se organizan alrededor del anillo que rodea la fuente, ya sea en el pequeño muro que recorre casi el perímetro de la plaza, o en las mesas de los cafés.

Entre los primeros se encuentran parejas o grupos de jóvenes que conversan o se apiñan en torno a la pantalla de un ordenador portátil o un teléfono móvil “inteligente”, parejas de ancianos, parejas adultas o mujeres acompañadas de niños. Los segundos conversan acerca de negocios o situaciones personales mientras toman un café, un jugo o una cerveza.

En este espacio es común ver a los niños juguetear e incluso aventurarse al interior del lecho de la fuente cuando ésta ha "bajado la marea" o se ha "secado" por unos minutos. Algunos introducen juguetes en el agua y los vuelven a retirar, otros realizan expediciones hacia la gran pantalla-muro de cristal que se encuentra adosado contra el extremo de la plazoleta en dirección a la plazoleta central y del cual baja el agua en cascada cuando el mecanismo se acciona.

Mientras tanto, los padres conversan y prestan atención a sus hijos. Lo mismo hacen los guardias de seguridad, quienes están prestos a intervenir de manera muy sutil cuando consideran que un niño puede estar poniéndose en peligro o realizando alguna acción que rompe el orden de la plazoleta. Cuando esto ocurre, el guarda en cuestión se acerca y le pide al niño, con marcada deferencia, que salga del espacio interior de la fuente.

En estos casos, como en cada situación de contacto entre un usuario de la plazoleta o visitante de alguno de los locales, se manifiesta una distancia cortés por parte de los empleados, todos uniformados, con respecto a quienes por el hecho de ser compradores han devenido clientes.

Distancia, contención, formalidad, son elementos esenciales de las sociabilidades que tienen lugar en este espacio. No sólo entre los empleados y los clientes, sino entre los usuarios mismos. La ausencia de las risas estentóreas y las afirmaciones en voz alta observadas en la plaza pública es signo de la inscripción de los sujetos en un sistema de conducta que está caracterizado por la tácita prohibición del despliegue espontáneo de la afectividad y por el apartamiento del cuerpo con respecto al de los otros (Heller, 1994). 
En el espacio arquitectónico del centro comercial, un principio de cortesía, autocontrol y distanciamiento modeliza todos los comportamientos. Este elemento central de las conductas y las sociabilidades está relacionado con el hábitus del comprador y asiduo del centro comercial (Bourdieu 1988), quien se inserta en el conjunto de las prácticas de apreciación y disfrute estético que supone el papel relevante que en la articulación del espacio cumple el diseño.

A partir de este elemento central se establecen un conjunto de diferencias tácitas entre los circunstantes, viandantes y compradores que están estructuradas sobre la base del consumo. La entrada a los locales (macro-objetos amplios, altos, caracterizados por la sensación de espacio y transparencia que es propia del centro comercial) está reducida a un flujo menor de la población, integrada por aquellos cuya capacidad adquisitiva les permite acceder a los bienes que se ofrecen en este dispositivo comercial. La espera o la conversación eventual en el anillo de la fuente son prácticas que parecen tener cariz de recreativas o propias del tiempo libre "de paso", pero que no alcanzan a presentar el aire de vocación y costumbre que se pudo apreciar para el caso de los que pasan la tarde o la mañana en la plaza pública. El tiempo que se consume en el café, en horas de oficina, es un lujo sutil de aquellos que disponen del mismo y del capital económico para acceder a la sensación de distinción que otorga la inserción en tales prácticas.

Posiblemente, la significativa población infantil que se observa en la plazoleta, alrededor de la fuente, hace una visita eventual, o relacionada con las diligencias y lugares de trabajo o de residencia de los padres. Con el paso de las horas, la población infantil se reduce, $\mathrm{y}$ al caer de la tarde son pocos los menores que se pueden observar. Este espacio sería un lugar eventual de paso y disfrute, cuya visita se encuentra determinada por la confluencia de los aspectos anteriormente mencionados, y por los horarios escolares y cotidianos de padres e hijos.

En lo que respecta a los jóvenes, que prefieren situarse en el espacio libre de los anillos de la fuente, todo parece indicar que asumen la plazoleta principalmente como sitio de encuentro y primera etapa en un itinerario de uso del tiempo libre que tiene al centro comercial como lugar idóneo para el esparcimiento y el ejercicio de la sociabilidad.

La población de las mesas de los cafés está integrada, en su mayor parte, por adultos, algunos mayores de cincuenta años, que en grupos pequeños conversan entre sí sin alzar la voz al nivel requerido como para que se tenga claro detalle de los pormenores de la charla. 
Por lo general, los circunstantes de la plaza, y especialmente aquellos que se sientan en las mesas delos cafés, están vestidos de acuerdo a la ocasión y portan accesorios que dan cuenta de buen gusto y de conocimiento de los códigos de la distinción en el vestir (gafas negras en las mujeres, que se portan a manera de diademas; pulseras, collares, relojes, estuches para dispositivos de comunicación, carteras de mano, etc). En las mesas se repite por doquier la práctica de poner las llaves del carro, el teléfono móvil, el estilógrafo o la pluma sobre las mismas. Este acto reflejo identifica a los circunstantes entre sí como poseedores de bienes materiales, producto del diseño, que se relacionan con el bienestar económico y con los valores y las formas de insertarse en el mundo social que se relacionan con éste.

Este sentido de la distinción y el privilegio se refuerza en el intercambio con los empleados, por medio de detalles tales como el goce de las decisiones de diseño que se encuentran en la base de la apariencia de los cafés, uno de los cuales ha generado un espacio que remite al universo de prácticas sofisticadas y exquisitas de la sala de té japonesa.

El resto de las prácticas que en estos espacios se realizan contribuye a reforzar lo que el espacio sugiere. La "orden" posiciona al cliente en un lugar de privilegio social, y el pago por medio de una carpeta con el signo de una compañía de crédito, sin que el dinero pase de mano a mano, introduce en el ritual del consumo el simulacro de un paso a segundo plano del dinero,lo que ennoblece ficcional pero efectivamente a los participantes en el intercambio.

Se podría decir que todos los micro-objetos y objetos equivalentes presentes en el dispositivo arquitectónico, comercial y de servicios de la plazoleta están orientados a sustentar esta fabricación de una relación en la que dos agentes distantes y sin lazos afectivos o comunitarios fuertes entre sí, obtienen el capital de un reconocimiento que les garantiza su valía como consumidores distinguidos.

Sobre esta base, los locales y firmas comerciales operan para conseguir, a cambio del ofrecimiento al cliente de dicho tipo de reconocimiento, las ganancias económicas que son su objetivo primordial.

\section{La ausencia de la memoria colectiva}

La Plazoleta de la fuente en Unicentro es un lugar relativamente reciente. Poca historia ha transcurrido en su seno, y las condiciones descritas arriba determinan el hecho de que no se presente como un sitio en el que se lleven a cabo prácticas políticas o de construcción de la memoria colectiva en las que, para efectos de este informe, valga la pena detenerse. 
Si existe una construcción de memoria, una producción de relatos que puedan valer como representantes del devenir, ésta se restringe a los sujetos en particular, o a los grupos que podrían visitar a menudo la plazoleta.

La ausencia de la función mediadora que los vendedores ambulantes tienen en la plaza pública, se manifiesta, en la plazoleta del centro comercial, por medio de la falta de conexión entre los distintos conjuntos de personas que se encuentran en ésta última en un momento determinado.

El flujo constante, los cortos períodos que tienen las estancias, el distanciamiento que funge como elemento esencial de la relación con los otros, se presentan como determinantes de la imposibilidad de que en este lugar, privado, organizado por la racionalidad comercial, ajeno para buena parte de la población en la ciudad (merced a la barrera simbólica que cierra el centro comercial a las clases menos favorecidas), se generen dinámicas e intercambios políticos y sociales susceptibles de servir de base a la constitución de cualquier narrativización de la historia comunitaria.

La actualización de la noción de comunidad (que se pudo observar en la plaza pública) aquí brilla por su ausencia, y quizá un signo idóneo de ello se puede apreciar en el hecho de que los guardas permanecen distantes y deferentes con respecto a los clientes y circunstantes, mientras que en el centro de la ciudad los policías conversan animadamente con el resto de los habitantes diurnos de la plaza.

En este sentido, la plazoleta del centro comercial es un lugar del presente y ajeno al mundo exterior, sin anclajes significativos con el pasado colectivo y ciudadano (Camps, 2000). Las tensiones y contradicciones del sistema social aquí son obliteradas tras la homogeneidad de los comportamientos, y merced a la primacía del individuo sobre el grupo o el clan que se instaura en el espacio comercial apenas el sujeto deviene cliente.

La dimensión cultural y ética de la participación en el espacio de la plazoleta es, por tanto, en gran medida, uniforme, y está mediada por la incomunicación entre individuos, grupos; por la comunicación endógena al interior de estos grupos, por y el despliegue en las prácticas de los signos del reconocimiento y el enclasamiento dependiendo de las posibilidades económicas de cada cual.

En este contexto, marcado por la posesión de los saberes y los recursos que brillan por su ausencia en el ambiente de la plaza pública, la conversación deviene ejercicio del despliegue de la posición social. Simultáneamente, se verifica un conjunto de prácticas propias de la inserción en el universo contemporáneo de la comunicación online y la constitución de las subjetividades a partir de la panoplia de dinámicas de la virtualidad y 
lasTIC's. Muestra de ello es la mencionada recurrencia de la observación de personas que realizan actividades en un ordenador (navegación en internet) o un teléfono inteligente. Esta posesión de los recursos actúa en el conjunto como elemento que coadyuva al distanciamiento. Las redes de solidaridades que se observaron en la plaza pública y que conviven con el comercio (de café, de llamadas telefónicas) no tienen lugar en el espacio privado de la plazoleta del centro comercial, en el que cada quien está supeditado a defenderse con lo que posee (los vendedores de llamadas a celular están a las afueras del centro comercial, en el espacio público).

La plazoleta del centro comercial es un dispositivo que no se deja apropiar enteramente y que es prestado a los clientes en la medida que lo permiten su capacidad adquisitiva o su capital cultural. El nivel de instrumentalización, de hacer con lo público, de modificar las funciones del espacio que se observó en la plaza pública, aquí no es posible. Los comportamientos y conductas reproducen el plan estratégico y la norma (gramática) que subyace a la producción del espacio sin alejarse mayormente de las expectativas que integran un código compartido del uso del espacio arquitectónico comercial.

Los objetos de diseño son los indicadores, mediadores, significantes y símbolos de estas prácticas de consumo del espacio semi-público (o privado comercial). Un principio de articulación estratégico, que aúna la oferta del placer estético, la promesa de la experiencia de la pertenencia al grupo de los privilegiados por su inserción en el universo del consumo de bienes y servicios suntuarios, y los ritmos de las dinámicas comerciales, laborales y académicas, estructura los tres órdenes objetuales (macro, micro, y objetos equivalentes) en un dispositivo dirigido con prevalencia a sujetos que se han investido de los roles sociales del consumidor y el cliente. En la plazoleta del centro comercial -al contrario de lo que ocurre en la plaza pública- la experiencia no se asume como un derecho, sino como un privilegio. Ahí, en donde es más incidente el diseño, se instauran de manera eficaz y sutil las distinciones que transmutan la ocupación momentánea del espacio en manifestación de la adscripción de los sujetos al código del consumo de los símbolos del status en la cultura del mall.

En síntesis, la plaza pública es para los que no tienen mucho, o acaso nada, y gozan de la libertad con respecto al tiempo que les provee esa falta de recursos y obligaciones. La plazoleta del centro comercial, que está en gran medida vedada a los anteriores (por su ubicación al sur de la ciudad, por el entramado de prohibiciones que sobre ésta pesan en términos simbólicos y económicos), objetos de intercambio en una relación con sus usuarios y clientes que está determinada por los espacios de ocio o las actividades que surgen del tiempo dedicado a la producción y a las obligaciones cotidianas. 


\section{Conclusiones}

La investigación hasta aquí realizada permite concluir que el diseño cumple la función de lenguaje formal a través del cual se constituyen objetos (significantes) que sirven como actualizaciones de la gramática social del centro comercial.

La confluencia de los objetos de diseño (en todos los niveles) y su articulación en el seno del centro comercial supone la producción de una sintaxis formal que debe ser decodificada por los usuarios. Lo que se transmite son los valores del buen gusto, la modernidad, la sofisticación, el lujo, el confort, la funcionalidad, la belleza.

Estos valores, representados por los objetos de diseño, son solidarios de los que competen a cada una de las marcas que poseen locales en el espacio privilegiado del mall. Si se tiene en cuenta que los objetos que ofrecen los locales también son objetos de diseño, se hace posible comprender que la relación dinámica entre los distintos niveles de diseño es, en gran medida, la esencia de la modelización del tipo de experiencia que los centros comerciales ofrecen a sus usuarios.

Como toda gramática y todo sistema de signos, este código del diseño en el centro comercial puede ser modificado dependiendo del emplazamiento y el target al que se dirige cada dispositivo arquitectónico comercial. En esas modificaciones descansa el estilo de cada espacio específico.

Así mismo, la consciencia del valor del diseño en la definición de un sentido de la experiencia se manifiesta de modo más marcado en los sitios en los que los consumos están ligados a altos niveles de escolaridad y de ingreso. En estos espacios y para los públicos que los visitan, la motivación fundamental de la visita corresponde a la posibilidad de ejercer prácticas y reafirmar representaciones que articulan el relato de la pertenencia a la clase privilegiada de los que saben gozar de la forma y la materialidad de los objetos, y traducir estos en símbolos de estatus.

De esta manera, los objetos de diseño no se muestran sólo como significantes que conforman sintaxis arquitectónico-comerciales y simbolizan hábitos y competencias propios de una clase específica de consumidores. También son los mediadores fundamentales del tipo de sociabilidades que se establecen entre quienes poseen los capitales y los saberes requeridos para inscribirse en los rituales de consumo característicos del centro comercial.

Por tanto, ya sea que funcionen semióticamente como íconos, símbolos o índices en un momento determinado, los objetos de diseño cumplen con la función semántica y referencial de aludir a una diferencia — adjudicable a los espacios en los que se encuentran y a sus poseedores y usuarios - que es al mismo tiempo cultural, económica, y social.

Allí en donde el diseño no se impone bajo el estatuto de dispositivo que fetichiza las funciones y la naturaleza de los objetostal y como ocurre en la plaza pública, no se van a encontrar los adeptos de su magia, gracias a la cual los sujetos experimentan el goce de su pertenencia al círculo de los elegidos (Mandoki, 2006). 
Es decir, el diseño es uno de los dispositivos fundamentales (si no el primordial) en el seno del proceso que configura en el espacio la manifestación física del sistema de valores que subyace al programa narrativo del sujeto contemporáneo.

Junto con este sistema de valores se constituyen inevitablemente el conjunto de las prácticas y las representaciones, de los hábitos, las expectativas y las necesidades para cuya realización o satisfacción ha surgido y evolucionado el centro comercial.

En este sentido, los objetos de diseño del centro comercial cumplen en la actualidad con una función que otrora le correspondiera a la imaginería religiosa de iglesias y catedrales. Son las señales que establecen el referente del espacio, y ordenan el universo simbólico del lugar, consagrándolo a un conjunto particular de ritos; arreglando, de antemano, las posibilidades de la conducta de los sujetos, y las modalidades de socialización que en su dominio pueden llevarse a cabo.

La discontinuidad que se observa entre la forma en que el diseño cumple estas funciones en el centro comercial, y su ausencia en el territorio de todos y de nadie que es la plaza pública (cada vez más habitada por los excluidos de los circuitos del centro comercial), es el signo de un desplazamiento fundamental que da cuenta de un cambio social: La constitución y el ejercicio de la individualidad y de las sociabilidades, de la participación de los sujetos en la vida pública, se han atomizado en el transcurso del último cuarto de siglo (Delgado, 1999). Dicha dispersión ha sido determinada por el crecimiento de las ciudades y la formación de distintas clases de suburbios, procesos interdependientes que alejan a los sujetos de distintas clases sociales.

El contraste entre lo que se puede observar en la plazoleta del centro comercial, y lo que se puede observar en la plaza pública, da cuenta de esta dispersión, una de cuyas consecuencias es el hecho de que la segunda ha cedido su función como lugar tradicional de encuentro, comercio, socialización, vida religiosa y política, anteel primero. La confirmación de la existencia de dicho desplazamiento y de la relación innegable que existe entre éste yciertas funciones asociadas a la práctica del diseño, permitirán seguir estableciendo conexiones que doten de un nuevo sentido al ejercicio sociológico.

\section{Notas}

1. La investigación en la que se enmarcan los resultados expuestos en este artículo se titula:

"Usos y significados de la plaza en el espacio público y en el centro comercial. Análisis de un desplazamiento en una perspectiva social y política”. Dicha investigación fue llevada a cabo por el grupo seminario "sociología del diseño", espacio académico vinculado al Departamento de Humanidades de la Universidad Icesi, que tiene por objetivo estudiar las relaciones entre el diseño y la sociología como prácticas complementarias de interpretación e intervención de la realidad.

2. Unicentro es un centro comercial que está en funcionamiento desde hace 30 años, su ubicación estratégica y su modelo de negocio lo han convertido en espacio icónico en la ciudad de Santiago de Cali. Referencias 


\section{Referencias}

Berger, P. y Luckmann, T. (2001). La construcción social de la realidad, Buenos Aires: Amorrortu editores.

Bourdieu, P. (1988). La distinción:criterio y bases sociales del gusto. Madrid: Taurus.

Camps, V. (2000) Elementos históricos del concepto de lo público, Cartagena: Memorias delV encuentro iberoamericano del tercer sector.

De Certeau, M. (2000). La invención de lo cotidiano, México: Universidad Iberoamericana.

Delgado, M. (1999). El animal público, Barcelona: Editorial Anagrama.

Duque, F. (2001). Arte público y espacio político, Madrid: Editorial Akal.

Eco, U. (2000). Tratado de semiótica general, Barcelona: Editorial Lumen.

Heller, A. (1994). Sociología de laVida Cotidiana, Barcelona: Editorial Península.

Heskett, J. (2005). El diseño en la vida cotidiana. Barcelona: Editorial Gustavo Gili.

Latour, B. (2008). Reensamblar lo social, Buenos Aires: Editorial Manantial.

Mandoki, K. (2006). Estética y juegos de la cultura: prosaica uno. Mexico: Siglo XXI.

Panofsky, E. (1998). El significado en las artes visuales. Madrid: Cátedra.

Martín, F. (2002). Contribuciones para una antropología del diseño. Barcelona: Editorial Gedisa.

Moles, A. (1975). Teoría de los Objetos, Barcelona: Editorial Gustavo Gili.

Pérgolis, J. C. (2000). La Ciudad: hábitat de diversidad y complejidad, Bogotá: Universidad Nacional de Colombia.

Press, M. y Cooper, R. (2009) El diseño como experiencia. Barcelona: Editorial Gustavo Gili.

Rosanvallon, P. (1995). La nueva cuestión social, Buenos Aires: Ediciones Manantial.

Sánchez, M. (2001). Morfogénesisdel Objeto de Uso, Bogotá: Universidad Jorge Tadeo Lozano.

Recibido: Septiembre 30 de 2012 Aprobado: Noviembre 10 de 2012 